NIST Handbook 150-2-2019

\title{
NVLAP \\ Calibration Laboratories
}

\author{
Barbara Belzer \\ Kari K. Harper \\ Titilayo Shodiya
}

This publication is available free of charge from: https://doi.org/10.6028/NIST.HB.150-2-2019

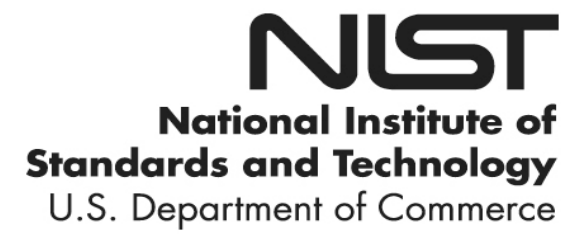




\title{
NVLAP \\ Calibration Laboratories
}

\author{
Barbara Belzer \\ Kari K. Harper \\ Titilayo Shodiya \\ National Voluntary Laboratory Accreditation Program \\ Standards Coordination Office \\ Laboratory Programs
}

This publication is available free of charge from:

https://doi.org/10.6028/NIST.HB.150-2-2019

July 2019

INCLUDES UPDATES AS OF 08-12-2019; SEE PAGE V

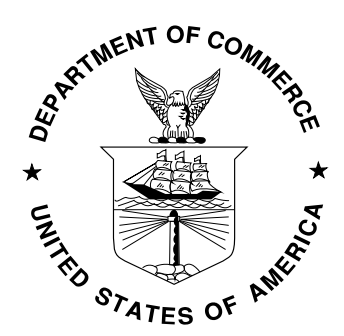

U.S. Department of Commerce Wilbur L. Ross, Jr., Secretary

National Institute of Standards and Technology Walter Copan, NIST Director and Undersecretary of Commerce for Standards and Technology 
Certain commercial entities, equipment, or materials may be identified in this document in order to describe an experimental procedure or concept adequately. Such identification is not intended to imply recommendation or endorsement by the National Institute of Standards and Technology, nor is it intended to imply that the entities, materials, or equipment are necessarily the best available for the purpose.

National Institute of Standards and Technology Handbook 150-2-2019 Natl. Inst. Stand. Technol. Handbook 150-2-2019, 41 pages (July 2019)

This publication is available free of charge from: https://doi.org/10.6028/NIST.HB.150-2-2019 


\section{NVLAP AND THE NVLAP LOGO}

The term NVLAP and the NVLAP logo are registered marks of the U.S. Federal Government, which retains exclusive rights to control the use thereof. Permission to use the term and symbol (NVLAP logo with approved caption) is granted to NVLAP-accredited laboratories for the limited purpose of announcing their accredited status, and for use on reports that describe only testing and calibration within the scope of accreditation. NVLAP reserves the right to control the quality of the use of the NVLAP term, logo, and symbol. 


\section{Contents}

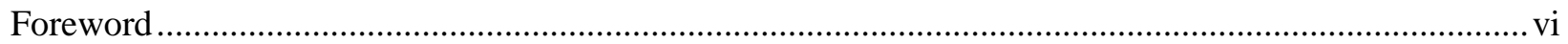

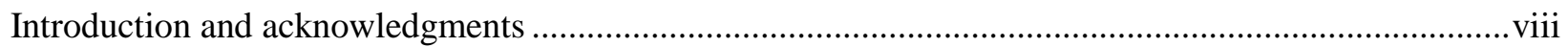

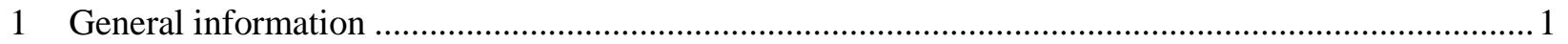

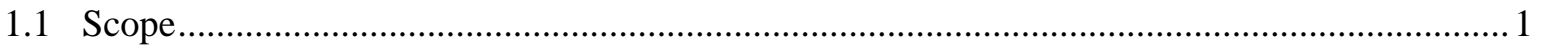

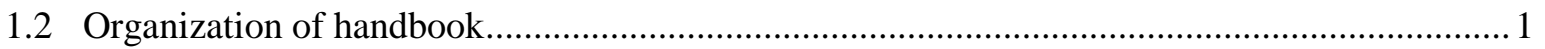

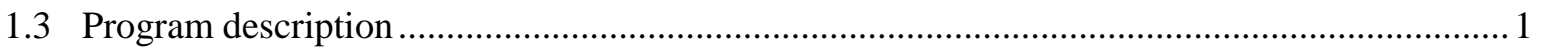

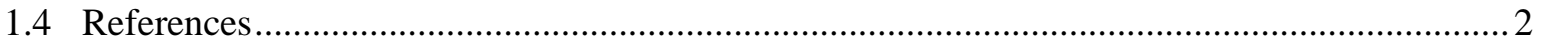

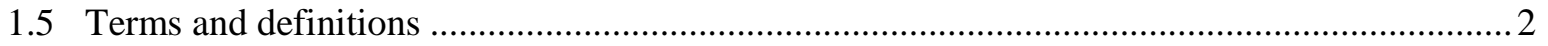

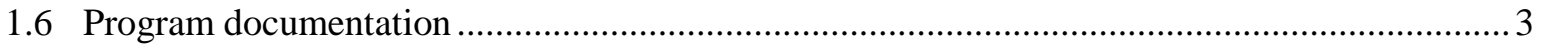

2 LAP establishment, development, and implementation ............................................................... 4

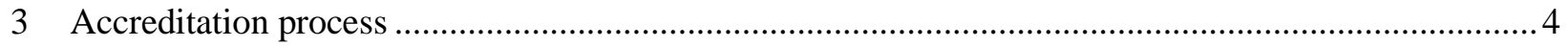

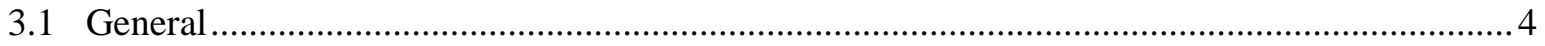

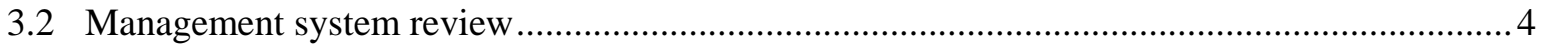

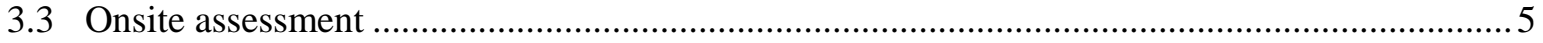

3.4 Laboratories seeking accreditation for calibrations with uncertainties near those provided by a

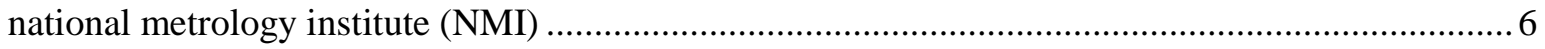

3.5 Policy on scopes of accreditation of calibration laboratories …............................................ 6

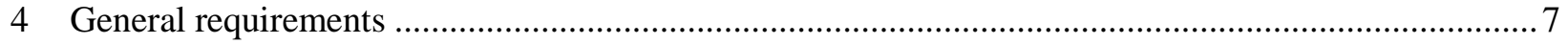

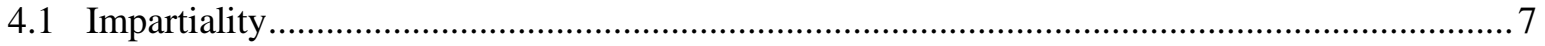

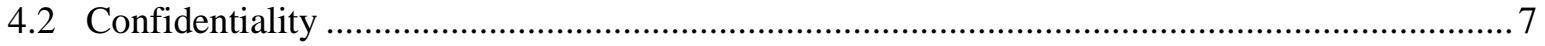

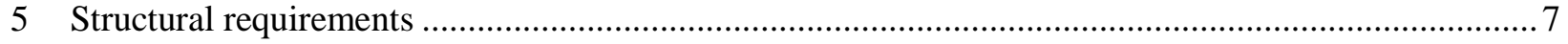

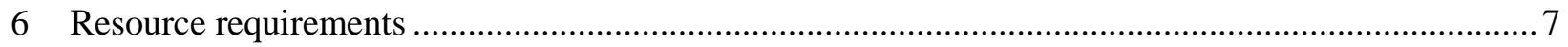

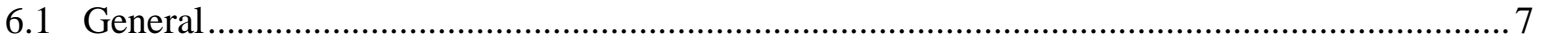

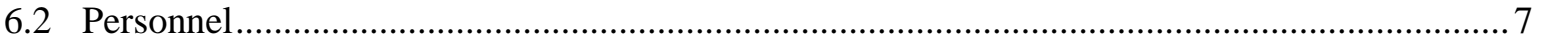

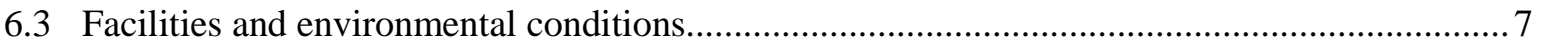

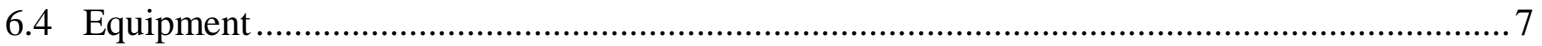

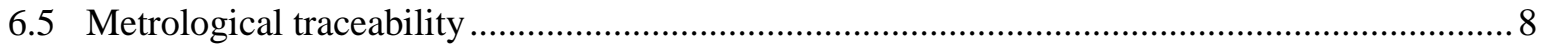

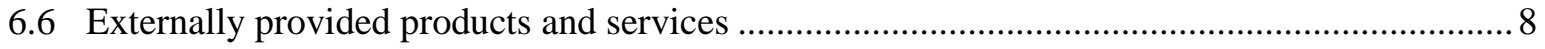

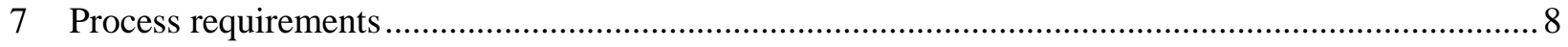

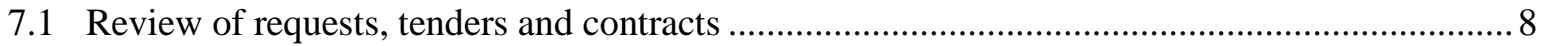

7.2 Selection, verification and validation of methods ................................................................. 8

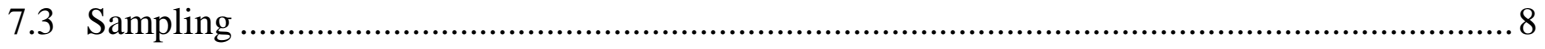

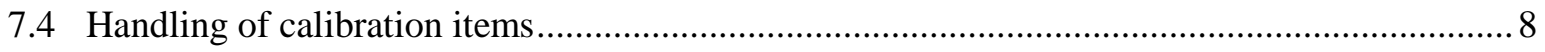




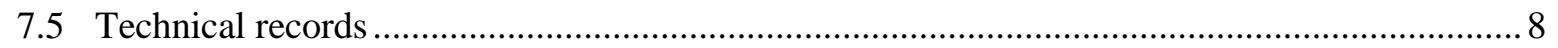

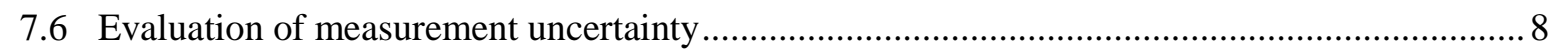

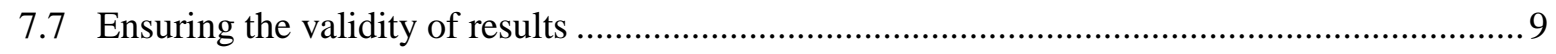

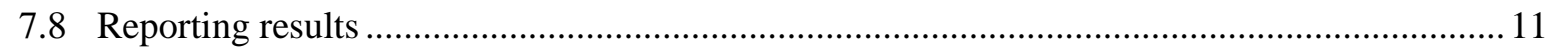

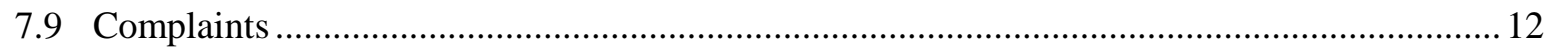

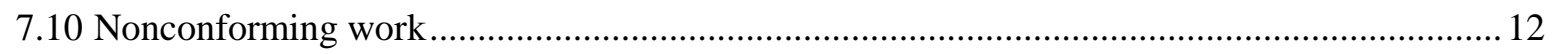

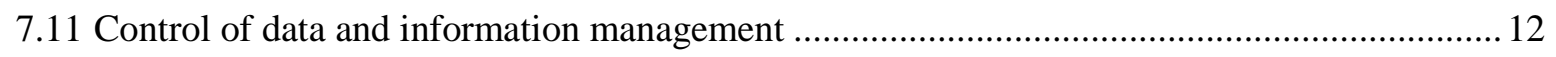

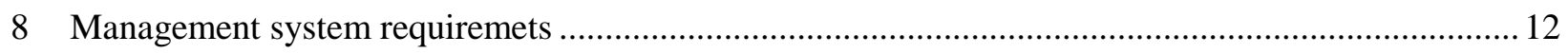

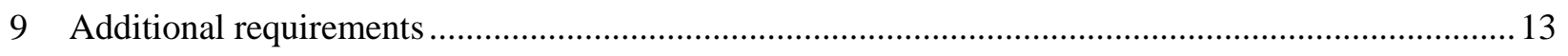

Annex A: ANSI/NCSL Z540-1-1994, Part I (normative)...................................................................... 14

Annex B: Dimensional measurements (normative) ............................................................................... 15

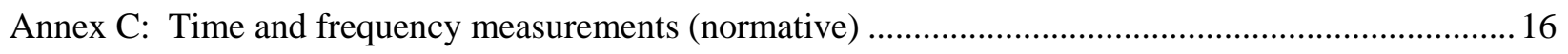

Annex D: Mechanical measurements (normative)............................................................................... 17

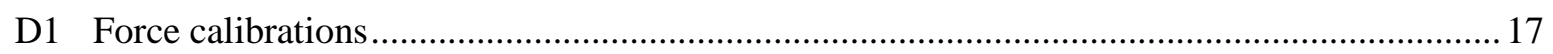

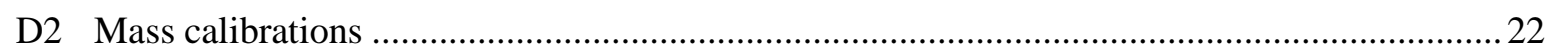

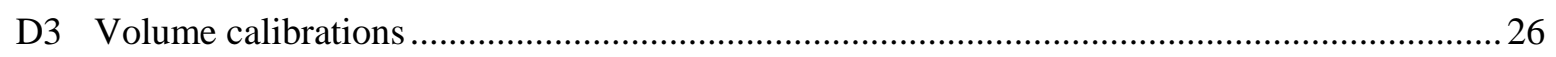

Annex E: Requirements for NVLAP-accredited legal metrology laboratories........................................ 29 


\section{Errata}

This table contains changes that have been incorporated into NIST Handbook 150-2. Errata updates can include corrections, clarifications, or other minor changes in the publication that are either editorial or substantive in nature.

\begin{tabular}{|c|c|l|c|}
\hline Date & Type & Change & Pages \\
\hline 08-08-2019 & Editorial & Updated requirements for 7.8.1 f) & 12 \\
\hline
\end{tabular}




\section{Foreword}

The NIST Handbook 150 publication series sets forth the procedures, requirements, and guidance for the accreditation of testing and calibration laboratories by the National Voluntary Laboratory Accreditation Program (NVLAP). The series is comprised of the following publications:

- $\quad$ NIST Handbook 150, NVLAP Procedures and General Requirements (hereafter referred to as NIST Handbook 150), which contains the general procedures and requirements under which NVLAP operates as an unbiased third-party accreditation body;

- $\quad$ NIST Handbook 150-xx program-specific handbooks, which supplement NIST Handbook 150 by providing additional requirements, guidance, and interpretive information applicable to specific NVLAP laboratory accreditation programs (LAPs).

The program-specific handbooks are not stand-alone documents, but rather are companion documents to NIST Handbook 150. They tailor the general criteria found in NIST Handbook 150 to the specific tests, calibrations, or types of tests or calibrations covered by a LAP.

NIST Handbook 150-2, NVLAP Calibration Laboratories, presents the technical requirements and guidance for the accreditation of laboratories under the NVLAP Calibration Laboratories LAP. The 2019 edition of NIST Handbook 150-2 supersedes and replaces the 2016 edition.

The handbook was revised with the participation of technical experts in the eight fields of calibration: dimensional, electromagnetics - dc/low frequency, electromagnetics - rf/microwave frequency, time and frequency, ionizing radiation, mechanical, optical radiation, and thermodynamic. The following significant changes have been made to this handbook with respect to the previous edition:

the numbering has been updated to reflect that used by ISO/IEC 17025:2017, General requirements for the competence of testing and calibration laboratories; (hereafter referred to as ISO/IEC 17025).

- The 2019 edition consolidates several technical guidance documents in the NIST Handbook 150-2 series into one document with a set of normative annexes:

- Annex A addresses the general accreditation requirements prescribed in ANSI/NCSL Z540-11994, Calibration Laboratories and Measuring and Test Equipment - General Requirements, Part I that are not directly addressed in ISO/IEC 17025.

- Annex B sets out technical requirements not covered in NIST Handbook 150 that are applicable to a laboratory recognized as competent to carry out dimensional calibrations.

- Annex C sets out technical requirements not covered in NIST Handbook 150 that are applicable to a laboratory recognized as competent to carry out time and frequency calibrations.

- Annex D sets out technical requirements not covered in NIST Handbook 150 that are applicable to a laboratory recognized as competent to carry out mechanical calibrations in the areas of force, mass, and volume.

- Annex E sets out technical requirements not covered in NIST Handbook 150 that are applicable to a laboratory recognized by the NIST Office of Weights and Measures and which performs legal metrology as a State weights and measures laboratory. 
Additional annexes covering the remaining fields of calibration will be published upon the completion of their review and updating. For areas where additional annexes have not yet been developed, it is suggested that laboratories continue to follow best practices for those fields of calibration.

Previously issued NVLAP lab bulletins pertaining to the Calibration Laboratories LAP have been incorporated into the appropriate clauses of the handbook. References and definitions have been updated, where necessary.

This handbook is also available on the NVLAP website (http://www.nist.gov/nvlap).

Questions or comments concerning this handbook should be submitted to NVLAP, National Institute of Standards and Technology, 100 Bureau Drive, Mailstop 2140, Gaithersburg, MD, 20899-2140; phone: 301-975-4016; fax: 301-926-2884; e-mail: nvlap@nist.gov. 


\section{Introduction and acknowledgments}

The Calibration Laboratories Accreditation Program was developed by the National Voluntary Laboratory Accreditation Program (NVLAP) at the National Institute of Standards and Technology (NIST) at the request of the National Conference of Standards Laboratories (now NCSL International). The goal of the program is to provide a means by which calibration laboratories can be assessed for competency. This voluntary program is not designed to impose specific calibration procedures or minimum uncertainties on applicant laboratories; instead, the program allows for all scientifically valid calibration schemes and requires that laboratories derive and document their calibration and measurement capabilities (CMCs).

In order to streamline program documentation, this handbook consolidates and replaces the previous technical guidance documents in the NIST Handbook 150-2 series. Clauses 3 through 8 of this handbook and the normative annexes include requirements for accreditation that are in addition to those found in ISO/IEC 17025. Annexes for the fields of calibration will be published as they are completed. The authors wish to thank the many NIST colleagues who provided technical contributions and reviews for the revision of this handbook. 


\section{General information}

\subsection{Scope}

1.1.1 This handbook specifies the technical requirements and provides guidance for the accreditation of laboratories under the NVLAP Calibration Laboratories Accreditation Program (Calibration LAP). It supplements the NVLAP procedures and general requirements found in NIST Handbook 150, by tailoring the general criteria found in NIST Handbook 150 to the specific calibrations and types of calibrations covered by the Calibration LAP.

1.1.2 NIST Handbook 150, ISO/IEC 17025, and this handbook constitute the collective body of requirements that must be met by a laboratory seeking NVLAP accreditation for the Calibration LAP.

1.1.3 This handbook is intended for information and use by accredited calibration laboratories, assessors conducting on-site assessments, laboratories seeking accreditation, other laboratory accreditation systems, users of laboratory services, and others needing information on the requirements for accreditation under the Calibration LAP.

1.1.4 Within this handbook, the term calibration report is used. Calibration certificate is an equally acceptable alternate name to use for such documents.

\subsection{Organization of handbook}

1.2.1 The numbering scheme used in clauses 4 through 8 of this handbook corresponds to that used in ISO/IEC 17025, General requirements for the competence of testing and calibration laboratories. In some cases, upper-level headings have been included for clarity with no additional text and refer the reader to ISO/IEC 17025 or to a specific technical annex.

1.2.2 The following technical annexes form a normative part of this handbook, meaning they contain provisions that laboratories must meet in order to conform to the requirements for accreditation:

- Annex A, Optional addition to scope of compliance with ANSI/NCSL Z540-1-1994, Part I;

- Annex B, Dimensional measurements;

- Annex C, Time and frequency measurements;

- Annex D, Mechanical measurements;

- Annex E, Requirements for NVLAP-accredited legal metrology laboratories.

1.2.3 The word shall is used throughout this handbook and describes mandatory requirements for accreditation. The word should is used where guidance is provided but does not preclude other acceptable practices.

1.2.4 A note (shown as NOTE and in a smaller font) contains additional information intended to assist the understanding or use of the document. Notes may provide clarification of the text, examples, and guidance; they do not contain requirements.

\subsection{Program description}

1.3.1 In 1994 the Calibration LAP began accepting applications for accreditation. Presently, the LAP encompasses eight fields of calibration covering a wide variety of parameters and includes accreditation 
in multifunction measuring and test equipment calibrations. Depending on the breadth of its calibration capabilities, a laboratory may seek accreditation for all or only selected parameters and/or calibrations offered in the Calibration LAP.

1.3.2 A laboratory may request to have parameters or calibrations added to the scope of the Calibration LAP. Any additions will be handled in accordance with NVLAP procedures for adding to or modifying an established LAP (see NIST Handbook 150, clause 2).

\subsection{References}

The following documents are referenced in this handbook and pertain to the overall Calibration LAP. For dated references, only the edition cited applies. For undated references, the latest edition of the referenced document (including any amendments) shall apply within one year of publication or within another time limit specified by regulations or other requirement documents.

References that are specific to a field of calibration are listed in the appropriate annex of this handbook. Additional references are posted on the Calibration LAP webpage on the NVLAP website, http://www.nist.gov/nvlap.

— ISO/IEC 10725:2017, General requirements for the competence of testing and calibration laboratories

— ANSI/NCSLI Z540.1-1994 (R2002), Calibration Laboratories and Measuring and Test Equipment General Requirements

- BIPM/IEC/IFCC/ISO/IUPAC/IUPAP/OIML, Guide to the Expression of Uncertainty in Measurement (GUM)

— ILAC-P14:01/2013, ILAC Policy for Uncertainty in Calibration

— ISO/IEC 17043:2010, Conformity assessment - General requirements for proficiency testing

- ISO 80000-1:2009, Quantities and units - Part 1: General laboratories

- NIST Handbook 150, NVLAP Procedures and General Requirements

\subsection{Terms and definitions}

For the purposes of this handbook, the terms and definitions given in NIST Handbook 150, ISO/IEC 17025, and the following apply.

\subsection{1}

\section{measuring and test equipment (M \& TE)}

All of the measuring instruments, measurement standards, reference materials, auxiliary apparatus, and instructions that are necessary to perform a measurement. This term includes measuring equipment used in the course of testing and inspection, as well as that used in calibration.

NOTE In the context of this handbook, the term measuring and test equipment is taken to encompass measurement instruments and measurement standards. Moreover, a reference material is considered to be a type of measurement standard. 


\subsection{2}

\section{precision}

Repeatability of measurement data; the similarity of successive independent measurements of a single magnitude generated by repeated applications of a process under specified conditions.

\subsection{3}

uncertainty, Type A (evaluation of)

Method of evaluation of uncertainty by the statistical analysis of a series of observations.

\subsection{4}

uncertainty, Type B (evaluation of)

Method of evaluation of uncertainty by means other than the statistical analysis of a series of observations.

\subsection{5}

\section{Field(s) of Calibration}

The top-level division of the broad range of measurement areas in which NVLAP accredits laboratories. The eight current fields of calibration in which NVLAP offers accreditation are: dimensional, electromagnetics - dc/low frequency, electromagnetics - rf/microwave frequency, time and frequency, ionizing radiation, mechanical, optical radiation, and thermodynamic.

\subsection{Program documentation}

\subsubsection{General}

Assessors use NVLAP checklists to ensure that each laboratory receives an assessment comparable to that received by others. Checklists assist assessors in documenting the assessment to the NVLAP requirements found in NIST Handbook 150, ISO/IEC 17025, and this handbook. Checklists contain definitive statements or questions about all aspects of the NVLAP requirements for accreditation and form part of the on-site assessment report (see NIST Handbook 150 clause 3.3.3).

\subsubsection{NVLAP General Criteria Checklist}

All NVLAP programs use the NVLAP General Criteria Checklist (formerly called the NIST Handbook 150 Checklist), which contains the requirements published in NIST Handbook 150 and ISO/IEC 17025. The checklist items are numbered to correspond to ISO/IEC 17025, clauses 4 through 8, and to NIST Handbook 150, annexes A, B, and E. Applicant or accredited laboratories may contact a NVLAP Program Manager to obtain a copy of this checklist.

\subsubsection{NIST Handbook 150-2 Checklist}

The NIST Handbook 150-2 Checklist addresses the requirements specific to the Calibration LAP (also referred to as the Calibration LAP Program-Specific Checklist). This checklist is available on the NVLAP website, http://www.nist.gov/nvlap.

\subsubsection{NVLAP Lab Bulletins}

NVLAP Lab Bulletins are issued to laboratories and assessors, when needed, to clarify program-specific requirements and to provide information about program additions and changes. 


\section{LAP establishment, development, and implementation}

This clause contains no information additional to that provided in NIST Handbook 150, clause 2.

\section{$3 \quad$ Accreditation process}

\subsection{General}

An overview of the laboratory accreditation process is provided in NIST Handbook 150, clause 3, and includes information pertaining to application for accreditation; on-site assessment; proficiency testing; accreditation decision; granting accreditation; renewal of accreditation; changes to scope of accreditation; monitoring visits; and suspension, denial, revocation, and voluntary termination of accreditation.

\subsubsection{Uncertainty budgets}

Laboratories shall submit uncertainty budgets for all requested CMCs with their application (new or at each renewal), and at any time when there are changes requiring a revision to the scope of accreditation. These shall be source documents that allow NVLAP staff and assessors to see calculations and constants. Do not convert a spreadsheet to pdf.

\subsubsection{Proficiency testing schedule}

With each renewal of accreditation, an accredited calibration laboratory shall provide an updated proficiency testing (PT) participation schedule, including evidence that previously planned activities have been completed. (See section 3.4.3.1.)

NVLAP Program Managers review the schedule and work with the laboratory as necessary to ensure that it adequately covers the scope of accreditation. During the onsite assessment, the assessors review the results of proficiency testing.

\subsection{Management system review}

Prior to applying to NVLAP for accreditation, a laboratory should have a fully implemented management system. If the management system of the laboratory uses different numbering than that of ISO/IEC 17025, the laboratory shall create a cross-reference document allowing the laboratory and a NVLAP assessor to verify that all requirements of clauses 4 through 8 of the international standard, as well as other applicable general NVLAP requirements, are met by the management system. Additionally, the locations within the laboratory's management system of the requirements given in this document, NIST Handbook 150-2, shall be provided in a cross-reference document. Note that the NVLAP General Criteria Checklist contains a column for the location of specific requirements within a laboratory's management system and, when this column is completed, it may serve as a core part of a cross-reference document. The checklist associated with this handbook may be similarly used.

NOTE A subset of requirements may be fulfilled by some laboratories without either program, policy, procedure, or resulting records. When completing the cross-reference document, for clauses where no documentation is required, it is acceptable to simply note met without documentation for the relevant clause. These will be assessed through discussion during the onsite assessment. Of course, when a program, policy, procedure, or record is called for in the requirements, these must be contained within the laboratory's quality system and its location must be noted in the cross-reference document. 


\subsection{Onsite assessment}

\subsubsection{Overview}

The on-site assessment process is described in NIST Handbook 150, 3.3. In most cases, the assessment of a calibration laboratory's full scope of accreditation requires several days at the laboratory's site with a team of assessors. The assigned team leader will coordinate activities with the laboratory and the assessment team.

\subsubsection{Assessment of field locations}

3.3.2.1 Many NVLAP-accredited laboratories provide calibrations in the field by sending a calibration technician from their main laboratory (the facility listed on the scope of accreditation) to a customer's site. When such a service is available for a given calibration, it is indicated on the scope of accreditation.

NOTE The additional requirements in the next subclause do not apply to field service calibrations performed by staff based at the main laboratory.

3.3.2.2 When a laboratory has technical aspects of its accredited work being performed at a field location by staff not based at the laboratory's main facility, the following requirements for NVLAP accreditation in a) through j) shall apply.

a) The laboratory shall demonstrate that all requirements of ISO/IEC 17025 and NIST Handbook 150 (other than the calibration) are being managed, performed, or otherwise controlled at the main facility.

b) The management system documentation shall clearly cover the processes for managing the field operations and identify the personnel specifically authorized to perform calibrations at the field locations.

c) For an initial accreditation of a calibration laboratory having one or more field locations, at least one field location shall be assessed by NVLAP.

d) In addition, all signatories shall be present at the initial assessment of the main facility.

e) The laboratory shall have field representatives (signatories and/or calibration technicians) available at the main facility for renewal assessments. In advance of the assessment, NVLAP will notify the laboratory which, or how many, of the field representatives are to be present.

f) As described in NIST Handbook 150, assessments are normally held biennially. During what would otherwise be a non-assessment year, an assessment of a field representative shall be done at his or her usual location if all field locations were not visited as part of the regular biennial assessment.

g) The laboratory shall demonstrate that field personnel are trained at the main facility, by staff from the main facility, or by field-based training staff specifically trained at the main facility.

h) The manner in which field personnel are trained shall be included in the training system documentation.

i) Calibration reports shall be issued by the main facility, indicate the physical locations where the calibrations were performed, and be signed by approved signatories. 
j) The laboratory shall have a defined interlaboratory comparison program between its headquarters and field locations.

\subsection{Laboratories seeking accreditation for calibrations with uncertainties near those provided by a national metrology institute (NMI)}

There are additional requirements in cases where laboratories are seeking accreditation for calibrations with uncertainties deemed by NVLAP to be near those provided by an NMI. These requirements include assessment by an NMI expert, detailed review of uncertainty budgets by NIST technical experts, and proficiency testing of rigor comparable to an NMI key or regional supplementary comparison.

\subsection{Policy on scopes of accreditation of calibration laboratories ${ }^{1}$}

Section 3.5 is informational in nature and is included as explanation to laboratories about the data NVLAP collects for the scopes of accreditation which represent their accredited capabilities.

3.5.1 The scope of accreditation of an accredited calibration laboratory shall include the calibration and measurement capability (CMC) expressed in terms of:
a) measurand;
b) calibration/measurement method/procedure;
c) type of instrument to be calibrated/measured;
d) measurement range and additional parameters where applicable, e.g., frequency of applied voltage;
e) uncertainty of measurement.

3.5.2 There shall be no ambiguity on the expression of the CMC on the scopes of accreditation and, consequently, on the smallest uncertainty of measurement that can be expected to be achieved by a laboratory during a calibration or a measurement. Particular care should be taken when the measurand covers a range of values. This is generally achieved through employing one or more of the following methods for expression of the uncertainty:
a) a single value, which is valid throughout the measurement range;
b) a range, in which case a calibration laboratory should have proper assumptions for the interpolation to find the uncertainty at intermediate values;
c) an explicit function of the measurand or a parameter;
d) a matrix where the values of the uncertainty depend on the values of the measurand and additional parameters;

${ }^{1}$ ILAC-P14:01/2013, ILAC Policy for Uncertainty in Calibration. 
e) a graphical form, providing there is sufficient resolution on each axis to obtain at least two

significant figures for the uncertainty.

Open intervals (e.g., “ $U<x$ ”) are not incorrect in the expression of CMCs.

NOTE In order to harmonize scopes within NVLAP, NVLAP may require a specific form of expressing range and/or uncertainty of measurement for any given parameter.

3.5.3 The uncertainty covered by the CMC shall be expressed, unless explicitly agreed upon, as the expanded uncertainty having a specific coverage probability of approximately $95 \%$. The unit of the uncertainty shall be the same as that of the measurand or in a term relative to the measurand, e.g., percent, $\mu \mathrm{V} / \mathrm{V}$, or part in $10^{6}$. This is excepted where U.S. industry practice dictates a specific expression of uncertainty.

\section{General requirements}

\subsection{Impartiality}

There are no requirements additional to those set forth in ISO/IEC 17025.

\subsection{Confidentiality}

There are no requirements additional to those set forth in ISO/IEC 17025.

\section{$5 \quad$ Structural requirements}

There are no requirements additional to those set forth in ISO/IEC 17025.

\section{Resource requirements}

\subsection{General}

There are no requirements additional to those set forth in ISO/IEC 17025.

\subsection{Personnel}

6.2.2 Should any requirements for competence for specific technical functions apply in a given field of calibration, those requirements will be detailed in the associated annex.

\subsection{Facilities and environmental conditions}

6.3.6 Any requirements for accommodation and environmental conditions in a specific technical area that go beyond those described in NIST Handbook 150 are given in the annex associated with that field of calibration.

\subsection{Equipment}

6.4.14 Any requirements for equipment in a specific technical area that go beyond those described in ISO/IEC 17025 are given in the annex associated with that field of calibration. 


\subsection{Metrological traceability}

There are no additional requirements to those set forth in ISO/IEC 17025 and NIST Handbook 150:2016 Annex B.

\subsection{Externally provided products and services}

There are no additional requirements to those set forth in ISO/IEC 17025.

\section{$7 \quad$ Process requirements}

\subsection{Review of requests, tenders and contracts}

There are no additional requirements to those set forth in ISO/IEC 17025.

\subsection{Selection, verification and validation of methods}

\subsubsection{Selection and verification of methods}

7.2.1.4 Any requirements for calibration methods and their selection in a specific technical area that go beyond those described in NIST Handbook 150 are given in the annex associated with that field of calibration.

\subsubsection{Validation of methods}

There are no additional requirements to those set forth in ISO/IEC 17025.

\subsection{Sampling}

There are no additional requirements to those set forth in ISO/IEC 17025.

\subsection{Handling of calibration items}

7.4.1 Any requirements for handling of calibration items in a specific technical area that go beyond those described in NIST Handbook 150 are given in the annex associated with that field of calibration.

\subsection{Technical records}

There are no additional requirements to those set forth in ISO/IEC 17025.

\subsection{Evaluation of measurement uncertainty ${ }^{2}$}

7.6.1 Calibration laboratories shall provide evidence that they can provide calibrations to customers so that measurement uncertainties equal those covered by the CMC.

2 ILAC-P14:01/2013, ILAC Policy for Uncertainty in Calibration. 
7.6.2 In the formulation of CMC, laboratories shall take notice of the performance of the "best existing device" that is available for a specific category of calibrations.

a) A reasonable amount of contribution to uncertainty from repeatability shall be included and contributions due to reproducibility should be included in the CMC uncertainty component, when available. The CMC quoted should include the contribution from a relatively ideal or best available device to be calibrated such that the CMC claimed is demonstrably realizable.

b) It is recognized that for some calibrations a "best existing device” does not exist and/or contributions to the uncertainty attributed to the device significantly affect the uncertainty. If such contributions to uncertainty from the device can be separated from other contributions, then the contributions from the device may be excluded from the CMC statement. For such a case, however, the scope of accreditation shall clearly identify that the contributions to the uncertainty from the device are not included.

NOTE The term "best existing device" is understood as a device to be calibrated that is commercially or otherwise available for customers, even if it has a special performance (stability) or has a long history of calibration.

\subsection{Ensuring the validity of results}

\subsubsection{Proficiency testing ${ }^{3}$}

Proficiency testing is an important tool to demonstrate laboratory competence and to assist with maintaining the quality of a laboratory's performance.

\subsubsection{Proficiency testing (PT) requirements}

\subsubsection{Frequency of PT}

A calibration laboratory shall meet the follow requirements for frequency of PT:

a) For those measurement parameters for which it is available, laboratories shall participate in appropriately rigorous PT (testing at the level of the laboratory's accredited capabilities).

b) An applicant laboratory shall show satisfactory participation in at least one PT prior to initial accreditation.

c) At a minimum, an accredited laboratory shall participate in proficiency testing in each field of calibration published on their scope at least once every four years. For some fields of calibration, e.g. ionizing radiation, NVLAP supports industry sector requirements for increased proficiency testing frequency. When this is the case, additional information is given in the technical annex for that field.

d) A laboratory shall meet any additional PT requirements stated in the annexes in this handbook related to the parameter(s) for which it is accredited.

${ }^{3}$ ILAC-P09:06/2014, ILAC Policy for Participation in Proficiency Testing Activities. 
e) As established in section 3.4 of this handbook, laboratories seeking accreditation for calibrations with uncertainties deemed by NVLAP to be near those provided by an NMI, proficiency testing of rigor comparable to an NMI key or regional supplementary comparison will be required, and at a specified frequency that may exceed that in 7.7.2.1a. Such PT may be identified by NVLAP in consultation with NIST experts for parameters where laboratories are operating at or near NIST uncertainties. In this case, the laboratory shall participate in the identified PT.

\subsubsection{Acceptable PT activities}

A calibration laboratory shall use one or more of the following types of proficiency testing:

a) PT through a provider accredited to ISO/IEC 17043 for the parameter being tested at the uncertainty level of that test, where that the accreditation to ISO/IEC 17043 is issued by a body which is signatory to a mutual recognition arrangement (MRA) for proficiency testing accreditation in a regional body recognized by the International Laboratory Accreditation Cooperation (ILAC); or

b) a PT which is coordinated through the NIST Office of Weights and Measures (OWM) Regional Measurement Assurance Program (RMAP); or

c) a PT or Measurement Assurance Program (MAP) offered through a NIST technical division; or

d) an exception: it is possible that PT providers that are not accredited may be acceptable. In this case, the non-accredited PT provider shall meet the requirements of ISO/IEC 17043, where applicable. The acceptability of proficiency tests from such providers will be determined by NVLAP in consultation with the laboratory.

\subsubsection{Reporting of PT}

A calibration laboratory shall meet the following requirements for reporting proficiency testing:

a) PT results shall be available for review during on-site assessments.

b) The E-normal value $\left(E_{n}\right)$ shall be reported for each measurement result, where applicable.

$E_{n}$ numbers are calculated using the equation:

$$
\mathrm{E}_{\mathrm{n}}=\frac{x-X}{\sqrt{U_{l a b^{2}+U_{r e f}{ }^{2}}}}
$$

where:

$x$ is the participant's result;

$X$ is the reference value;

$U_{l a b}$ is the expanded uncertainty of the participant's result; and

$U_{\text {ref }}$ is the expanded uncertainty of the reference value.

$\left|E_{n}\right| \leq 1.0$ indicates "satisfactory" performance.

$\left|E_{n}\right|>1.0$ indicates “unsatisfactory” performance. 
NOTE Where the proficiency test has multiple $E_{n}$ values for a range of measurements, allowance for a number of individual measurement $E_{n}$ values to be greater than 1 may be applied. This allowance is based on the coverage probability of $95 \%$ as long as sufficient (typically 10 or more) measurement points are taken for determination.

c) Laboratories are required to address unsatisfactory PT results. Records of corrective actions taken to address unsatisfactory results shall be available for review during assessments.

\subsubsection{Laboratory PT Plan}

A calibration laboratory shall have a PT plan meeting the following requirements:

a) An applicant calibration laboratory shall develop a proficiency testing participation plan, describing how the laboratory will meet requirements for minimum participation in PT given above.

b) With each renewal of accreditation, an accredited calibration laboratory shall provide an updated PT participation schedule, including evidence that planned activities have been completed. NVLAP Program Managers review the schedule and work with the laboratory as necessary to ensure that it adequately covers the scope of accreditation. During the onsite assessment, the assessors review the results of proficiency testing.

c) The PT plan shall reflect the laboratory's past year PT activities as well as planned activities for the next three years to provide continuing evidence that technical competence is being maintained.

d) The PT plan shall be regularly reviewed by the laboratory in response to changes in scope, staffing, methodology, instrumentation, etc.

NOTE Review of the PT plan by the laboratory may occur as part of the management review process.

\subsection{Reporting results}

\subsubsection{Calibration measurement results ${ }^{4}$}

a) The measurement result shall normally include the measured quantity value y and the associated expanded uncertainty U. In calibration certificates the measurement result should be reported as $\mathrm{y} \pm \mathrm{U}$ associated with the units of $\mathrm{y}$ and $\mathrm{U}$. Tabular presentation of the measurement result may be used and the relative expanded uncertainty $\mathrm{U} /|\mathrm{y}|$ may also be provided if appropriate.

b) The coverage factor and the coverage probability shall be stated on the calibration certificate. To this an explanatory note shall be added, which may have the following content:

"The reported expanded uncertainty of measurement $(U)$ is stated as the standard uncertainty of measurement multiplied by the coverage factor $k$ such that the coverage probability corresponds to approximately $95 \%$.”

NOTE For asymmetrical uncertainties other presentations than $y \pm U$ may be needed. This concerns also cases when uncertainty is determined by Monte Carlo simulations (propagation of distributions) or with logarithmic units.

\footnotetext{
${ }^{4}$ ILAC-P14:01/2013, ILAC Policy for Uncertainty in Calibration.
} 
c) The numerical value of the expanded uncertainty shall be given to, at most, two significant figures.

d) The numerical value of the measurement result shall in the final statement be rounded to the least significant figure in the value of the expanded uncertainty assigned to the measurement result.

e) Where displayed values have been rounded, that rounding shall be applied when all calculations have been completed; resultant values may then be rounded for presentation.

NOTE For further details on rounding, see ISO 80000-1:2009.

f) Contribution to the uncertainty stated on the calibration certificate shall include relevant short-term contributions during the calibration and contributions that can reasonably be attributed to the customer's device

g) Where applicable, the uncertainty shall cover the same contributions to uncertainty that were included in evaluation of the CMC uncertainty component, except that uncertainty components evaluated for the best existing device shall be replaced with those of the customer's device. Therefore, reported uncertainties tend to be larger than the uncertainty covered by the CMC. Random contributions that cannot be known by the laboratory, such as transport uncertainties, should normally be excluded in the uncertainty statement. If, however, a laboratory anticipates that such contributions will have significant impact on the uncertainties attributed by the laboratory, the customer should be notified according to the general clauses regarding tenders and reviews of contracts in ISO/IEC 17025.

h) As the definition of CMC implies, accredited calibration laboratories shall not report a smaller uncertainty of measurement than the uncertainty of the CMC for which the laboratory is accredited.

\subsubsection{Additional requirements for specific technical areas}

Information regarding additional requirements on reporting of results in a specific technical area, if any, are given in the annex associated with that area.

\subsection{Complaints}

There are no requirements additional to those set forth in ISO/IEC 17025.

\subsection{Nonconforming work}

There are no requirements additional to those set forth in ISO/IEC 17025.

\subsection{Control of data and information management}

There are no requirements additional to those set forth in ISO/IEC 17025.

\section{Management system requirements}

There are no additional requirements to those set forth in ISO/IEC 17025 in any of the management system requirement subsections 8.1 through 8.9 . 


\section{$9 \quad$ Additional requirements}

The following annexes contain requirements that are specific to each technical program area and its associated calibration methods. 


\title{
Annex A: ANSI/NCSL Z540-1-1994, Part I (normative) \\ [Optional addition to scope: compliance with ANSI/NCSL Z540-1-1994, Part I]
}

\begin{abstract}
A.1 General
This annex addresses the general accreditation requirements prescribed in ANSI/NCSL Z540-1-1994, Calibration Laboratories and Measuring and Test Equipment - General Requirements, Part I that are not directly addressed in ISO/IEC 17025. Laboratories wishing to be recognized for compliance with the requirements of ANSI/NCSL Z540-1-1994, Part I shall meet the requirements listed below, in addition to those found in ISO/IEC 17025 and this handbook.
\end{abstract}

\section{A.2 Management requirements for accreditation}

A.2.1 The quality system adopted to satisfy the requirements of ANSI/NCSL Z540-1-1994 shall be reviewed at least once a year by the management to ensure its continuing suitability and effectiveness and to introduce any necessary changes or improvements.

\section{A.3 Calibration methods and method validation}

a) Calibration procedures shall contain the required range and tolerance or uncertainty of each item or unit parameter being calibrated or verified.

b) In addition, the procedures shall contain the generic description of the measurement standards and equipment needed with the required parameter, range, tolerances or uncertainties, and specifications for performing the measurement of the calibration or verification, and/or representative types (manufacturer, model, option) that are capable of meeting the generic description for the measurement standards.

c) The procedures shall be consistent with the accuracy required, and with any standard specifications relevant to the calibrations/verifications concerned.

\section{A.4 Equipment}

a) Tamper-resistant seals shall be affixed to operator-accessible controls or adjustments on measurement standards or measuring and test equipment which, if moved, will invalidate the calibration.

b) The laboratory's calibration system shall provide instructions for the use of such seals and for the disposition of equipment with damaged or broken seals.

\section{A.5 Reporting the results}

In addition to the list of required items in 7.8 of ISO/IEC 17025, each calibration report shall include a statement that the calibration report shall not be reproduced except in full, without the written approval of the laboratory. 


\section{Annex B: Dimensional measurements (normative)}

\section{B.1 General}

This annex contains specific technical requirements not covered in ISO/IEC 17025 that are applicable to a laboratory recognized as competent to carry out dimensional calibrations.

\section{B.2 Accommodation and environmental conditions}

\section{B.2.1 Thermal conditions affecting artifacts}

a) Measurement results are generally reported as the length at $20^{\circ} \mathrm{C}$. If measurements are made at temperatures other than $20^{\circ} \mathrm{C}$, the uncertainties of the appropriate thermal corrections for the artifacts shall be included in the total uncertainty.

b) For comparison measurements, the uncertainty component shall reflect the uncertainty in the thermal corrections of both the master and unknown artifacts, as well as the temperature difference between them, and the uncertainty of the temperature sensor used.

\section{B.2.2 Ambient temperature considerations}

a) The temperature stability of the environment shall be sufficient for the gage and measurement system to be in thermal equilibrium.

b) If measurements are made in slowly changing environments, a suitable measurement model, which includes the effects of the drift, shall be used. Theoretical and experimental verification of the model should be available.

B.2.3 For typical gages made of well-characterized materials (steel, carbide, or ceramic), $\pm 10 \%$ shall be used as the standard uncertainty of the thermal expansion coefficient unless there is documentation of a lower value.

B.2.4 The laboratory shall have a documented policy regarding responses to environmental conditions outside of specified range.

\section{B.3 Equipment}

B.3.1 The laboratory shall have temperature-measuring capabilities suitable for the calibration procedure and the desired measurement uncertainty.

NOTE Calibrations involving direct comparisons of artifacts of similar size and materials will, in general, have modest requirements. Absolute calibrations or comparisons between artifacts of different sizes and/or materials will require more accurate temperature measurement or adjustment of the measurement uncertainty.

B.3.2 A laboratory that makes mechanical comparisons of masters and test pieces of dissimilar materials shall have force measuring equipment to determine the force on the probe or probes. A correction for differential probe penetration should be applied as long as the probe has maintained its desired geometry. 


\section{Annex C: Time and frequency measurements (normative)}

\section{C.1 General}

This annex contains specific technical requirements not covered in ISO/IEC 17025 that are applicable to a laboratory recognized as competent to carry out time and frequency calibrations.

\section{C.2 Measurement traceability}

C.2.1 Because a waveform is a set of ordered pairs (i.e., time, voltage), traceability of both the time and voltage shall be in place.

NOTE This is normally demonstrated by calibration of a high-speed oscilloscope or calibration of a fast-rise generator by an external source meeting the requirements in NIST Handbook 150, Annex B.

C.2.2 Laboratories that utilize a Global Positioning System Disciplined Oscillator (GPSDO) to establish traceability shall:

a) have procedures in place to ensure GPS is locked and working properly;

b) consider the internal oscillator's short-term stability and measurement time in the laboratory's reported uncertainty. 


\section{Annex D: Mechanical measurements (normative)}

\section{D1 Force calibrations}

\section{D1.1 General}

The purpose of this section is to specify the technical criteria that shall be met when performing calibrations of force-measuring instruments.

\section{D1.2 Procedural standard methods}

All measurement procedures, accommodation and environmental conditions, instruments and equipment used, and the reporting of results when conducting a force-related calibration, shall comply with one or both of the following referenced standards documents, except in special circumstances (see below):

ASTM E74, Standard Practices of Calibration and Verification of Force-Measuring Instruments

ISO 376: Metallic materials- Calibration of force-proving instruments used for the verification of uniaxial testing machines

Special circumstances: Laboratories may be accredited to other documentary standards methods or laboratory-developed methods once they have been assessed for them.

\section{D1.3 Accommodation and environmental conditions}

D1.3.1 All instruments shall be allowed sufficient time to reach room temperature prior to calibration.

D1.3.2 The recommended calibration temperature is $23^{\circ} \mathrm{C}\left(73.4^{\circ} \mathrm{F}\right)$, however, calibrations shall be conducted within the temperature ranges specified by the procedural method used.

D1.3.3 During calibration, the temperature shall be monitored at a location that reflects the temperature of the instrument.

D1.3.4 Temperature stability shall be maintained in accordance with the procedural method used.

D1.3.5 If the temperature variations exceed $\pm 0.2^{\circ} \mathrm{C}$ during the calibrations of non-temperature compensated instruments such as proving rings, the calibration data shall be corrected in accordance with the applicable force calibration standard.

\section{D1.4 Equipment}

\section{D1.4.1 Primary force standards (ASTM E74)}

D1.4.1.1 A laboratory that performs primary force standards calibrations shall directly apply a deadweight force without intervening mechanisms such as levers, hydraulic multipliers, or the like, whose mass has been determined by comparison with mass reference standards traceable to the International System of Units (SI). 
D1.4.1.2 Primary force standard deadweight machines shall not have any mechanism for amplifying the force such as levers, hydraulic multipliers or the like, or any mechanism that counterbalances the frame (or tare).

D1.4.1.3 Weights used as primary standards in deadweight machines shall be made of rolled, forged, or cast metal.

D1.4.1.4 The surface roughness of the weights shall meet the requirements of the applicable force calibration standard.

D1.4.1.5 If the weights are plated or coated, the finish shall be of a proven design and of a material such as cadmium or nickel-chromium.

D1.4.1.6 The forces developed by the weights shall be determined using formula 1 ,

$$
F=m g\left[1-\left(\rho_{\mathrm{a}} / \rho_{\mathrm{w}}\right)\right]
$$

where

$$
\begin{aligned}
& F=\text { force }(\mathrm{N}), \\
& m=\text { mass }(\mathrm{kg}), \\
& g=\text { local acceleration due to gravity }\left(\mathrm{m} / \mathrm{s}^{2}\right), \\
& \rho_{\mathrm{a}}=\text { density of air, and } \\
& \left.\rho_{\mathrm{w}}=\text { density of the weight (same units as } \rho_{\mathrm{a}}\right) .
\end{aligned}
$$

D1.4.1.7 This requires that the laboratory shall have knowledge of the local gravity, its uncertainty, and the local air buoyancy correction.

D1.4.1.8 The masses of the weights shall be known to within $0.005 \%$ of their nominal values by comparison to reference standards traceable to the International System of Units (SI). The local value of the acceleration due to gravity, calculated within $0.0001 \mathrm{~m} / \mathrm{s}^{2}(10 \mathrm{mGal})$, may be obtained from the National Geodetic Information Center, National Oceanic and Atmospheric Administration.

D1.4.1.9 The laboratory shall keep records of the calibration of all weights used as standards.

D1.4.1.10 The uncertainty of the vertical component of force applied by the weights shall also be stated in the laboratory records and in reports of calibration.

D1.4.1.11 The masses of the weights shall be determined initially and the determination repeated if damage or disassembly of the machine occurs.

D1.4.1.12 Verification of force realization shall be demonstrated through an intercomparison program as outlined by the laboratory's quality system.

\section{D1.4.2 Secondary force standards (ASTM E74)}


D1.4.2.1 Secondary force standards shall have been calibrated against primary force standards, with the exception that secondary force standards having capacities exceeding $1000000 \mathrm{lbf}(4.4 \mathrm{MN})$ may be calibrated against a combination of several lower-capacity secondary force standards loaded in parallel.

D1.4.2.2 If several secondary force standards are combined and loaded in parallel to meet special needs for high capacities exceeding $1000000 \mathrm{lbf}(4.4 \mathrm{MN})$ :

a) those secondary force standards shall have equal compliance, and

b) forces shall be applied equally to each of those secondary force standards.

D1.4.2.3 Secondary force standards used shall have a suitable force calibration frame or mechanism to ensure an axial force application to the unit under test. The secondary system should exhibit no parasitic, frictional or mechanical losses during use.

D1.4.2.4 Any perturbations shall have been characterized.

\section{D1.4.3 Uncertainty of the applied forces}

The uncertainty of the applied forces generated shall be determined using appropriate methods, such as recommended in ASTM E74 and ISO 376.

\section{D1.4.4 Overloaded or repaired instruments}

D1.4.4.1 Any force standard or multiplying system that is repaired or modified in a way that may result in changes in the calibration curve shall be recalibrated prior to use.

D1.4.4.2 Any instrument that sustains an overload that produces a change in the zero-force output of $1 \%$ or more shall be recalibrated prior to use.

\section{D1.4.5 Accessory hardware}

All calibration hardware that is subject to calibration forces such as coupling nuts, pull-rods, adapters, etc., shall be clearly labelled with the maximum allowable force they can sustain.

\section{D1.4.6 Electrical instruments}

The electrical instrumentation used to calibrate force-measuring instrumentation shall comply with the requirements specified by the procedural method used.

\section{D1.5 Calibration}

\section{D1.5.1 Distribution and number of calibration forces}

The calibration forces shall be distributed over the full range of the force-measuring instrument as specified by the procedural method used. Note that the requirements of ASTM E74 and ISO 376 differ.

\section{D1.5.2 Randomization of force application conditions}


Randomization of force application conditions is of primary importance. The instrument undergoing calibration shall be rotated in the calibration machine and subjected to other randomizations in accordance with the procedural method used. 


\section{D1.6 Records}

All measurements shall be appropriately recorded and maintained in accordance with the procedural method used where those requirements exceed those of ISO/IEC 17025.

\section{D1.7 Reporting the results}

D1.7.1 In addition to the report requirements of ISO/IEC 17025, the laboratory shall provide calibration reports that conform to the requirements of ASTM E74, ISO 376 or both.

D1.7.2 The calibration report shall state which documentary standard(s) was (were) followed.

D1.7.3 In cases where other procedural standards are followed, the calibration report shall, at a minimum, contain the following information:

a) manufacturer and serial number of the instrument calibrated;

b) type of reference standard used (i.e., primary standard, secondary standard), including the uncertainty in the applied force;

c) if critical to transducer performance, identification of the force application fittings used;

d) temperature at which the calibration was performed, including limits of temperatures variations during the calibrations;

e) listing of the calibration forces applied and deflections observed;

f) the calibration curve, including the method of analysis used to obtain the curve, and the deviations of the experimental data for the fitted curve;

g) the uncertainty associated with the calibration results and limits of assigned force ranges if such limits are required. 


\section{D2 Mass calibrations}

\section{D2.1 General}

The purpose of this annex is to specify the criteria needed to assess the competence of a calibration laboratory that performs mass calibrations. Note that the echelon classifications referenced below are further defined in NIST Handbook 143, Table 4.

\section{D2.2 Accommodation and environmental conditions}

D2.2.1 To be deemed capable of making adequate measurements, calibration laboratories shall provide an environment with adequate environmental controls appropriate for the level of measurements to be made, according to echelon classes.

D2.2.2 The environmental conditions shall be within the specifications of the weighing instruments where applicable.

D2.2.3 Instruments measuring environmental conditions shall be used in close proximity to the balance being used. For Echelon I, temperature may be measured inside the weighing chamber when there is a difference between the air temperature in the balance chamber and the surrounding area.

D2.2.4 The laboratory shall maintain limited access to the calibration area and minimize contamination (maintain a clean surface) for locations where calibration items are being tested.

D2.2.5 Vibration shall not diminish the performance of precision analytical balances and mass comparators.

D2.2.6 Undesirable effects due to static electricity shall be controlled, if needed, with methods such as humidity, anti-static, deionizing radiation devices, the grounding of balances or operators, or with the use of special conductive flooring, and selection of proper clothing for staff.

D2.2.7 Laboratories shall evaluate the level of significance for buoyancy corrections for all mass calibrations.

\section{D2.3 Procedures and method validation}

D2.3.1 The procedures and formula chosen for the mass measurement, the reference standard(s) to be used, and the equipment to be used for a calibration shall provide acceptable levels of uncertainty for that calibration.

D2.3.2 A documented procedure, compliant with the requirements of OIML or ASTM documentary standards for mass, shall be available in the laboratory to determine the correct algorithm to be used for the specific calibration.

\section{D2.4 Equipment}

D2.4.1 Due to comparison methods and calculations used in mass calibration, the uncertainty of measurement results from auxiliary instruments for Echelons I and II, (e.g., scale, analytical balance, mass comparator) is less important than the precision of the instrument. However, if such equipment used for comparison are repaired or serviced:

a) they shall be reevaluated to ascertain the current level of precision prior to use, and 
b) the uncertainty estimate shall reflect the post-repair performance.

D2.4.2 The precision of the scale, analytical balance, or mass comparator, as determined through appropriate process control charts, shall be suitable to the echelon class for which it is used.

D2.4.3 For an application where external standards are used for comparison, appropriate control charts shall be maintained to evaluate the process standard deviation.

\section{D2.4.4 Balances}

D2.4.4.1 Balances used as a direct comparison to the mass unit shall be calibrated prior to use.

D2.4.4.2 For an application requiring balance accuracy, the laboratory shall choose appropriate and correct calibration procedures and calculations.

D2.4.4.3 Balances used as dividers and multipliers of the mass unit shall be capable of providing the appropriate uncertainty and linearity requirements of the echelon class for which they are used.

D2.4.4.4 Calibration of built-in standards shall be performed periodically and shall be verified prior to use. History from measurement control programs (surveillance testing) may be used to determine calibration intervals.

\section{D2.4.5 Environmental sensors}

D2.4.5.1 Measurement results data from instruments used to monitor environmental conditions in the laboratory shall be traceable to the International System of Units (SI) through a suitable national laboratory (directly or by way of an accredited laboratory).

D2.4.5.2 These instruments shall be recalibrated periodically unless intrinsic (defining) standards are employed.

D2.4.5.3 Calibration and intercomparison periods shall be documented by the laboratory.

D2.4.5.4 For intrinsic standards, data from intercomparison with standards of known measurement values shall be available.

D2.4.5.5 Means shall be provided to measure barometric air pressure, air temperature, and relative humidity of the laboratory environment adequate to the method used.

D2.4.5.6 Documentation of the uncertainty and traceability of these environmental measurement results shall be maintained.

\section{D2.5 Standards}

D2.5.1 Suitable reference standards shall be available at each echelon and range for which the laboratory is accredited.

D2.5.2 Sufficient historical data and uncertainty analysis shall be available to support the standards used at each level of a traceability hierarchy.

D2.5.3 Suitable calibration intervals shall be documented and ensured. 
D2.5.4 For Echelon I, the laboratory shall state the presence of a possible systematic error in the combined uncertainty associated with the use of an assumed or reported density in the primary or reference standards (additional type B component) or the laboratory shall have appropriate means to measure the density of mass standards.

D2.5.5 Each mass standard used as a reference standard by the laboratory shall be calibrated by a National Metrology Institute or by an accredited laboratory with capability adequate to sustain the uncertainty required and maintain traceability to International System of Units (SI).

D2.5.6 The laboratory shall provide evidence, such as periodic surveillance, that the mass standards are, in principle, stable and acceptable for providing calibration services at each echelon for which they are used.

\section{D2.6 Handling of test and calibration items}

D2.6.1 The laboratory shall have documented procedures to ensure adequate chain-of-custody of calibration items if required by law.

D2.6.2 The laboratory shall document appropriate procedures to ensure that cleaning or adjustments, if performed, ensures the integrity of the standards, and to provide for thermal and other environmental conditioning, where appropriate.

D2.6.3 The laboratory shall allow adequate stabilization time for mass standards to ensure environmental and thermal stability prior to calibration.

D2.6.4 Documented procedures to ensure adequate tracking of calibration items shall be appropriate to the class of mass standard. Strings, tags, or labels fastened to the standard are inappropriate for all types of mass standards.

\section{D2.7 Assuring the quality of test and calibration results}

D2.7.1 Appropriate measurement control programs shall be in place and available for review for each echelon and nominal mass range for which calibration data is provided. Appropriate data include balance standard deviations that represent measurement process variation using well-characterized check standard values.

D2.7.2 Measurement control techniques shall exhibit results consistent with the procedures used to perform calibrations and be integrated into the measurement procedures to accurately reflect the measurement process.

D2.7.3 For those situations in which statistical information is not inherent to the process, i.e., simple measurements without built-in redundancy checks:

a) additional measurements shall be made to provide experimental characterization of the measurement sufficient for an adequate estimation of the process uncertainty;

b) those data shall be available for review.

\section{D2.8 Reporting the results}

D2.8.1 Calibration reports shall describe the mass standards mentioned in the report with sufficient detail to avoid any ambiguity. 
D2.8.2 In addition to the general report requirements of ISO/IEC 17025, for Echelon I and II calibration, additional items to be included on a test report, are:

a) mass (true mass) values;

b) conventional (apparent) mass values versus appropriate reference density;

c) reference density;

d) uncertainties;

e) material;

f) thermal coefficient of expansion (if used in calculations);

g) construction;

h) density (assumed or measured, along with measurement method);

i) any identifying markings;

j) tolerances, if appropriate;

k) magnetic susceptibility of mass standards, if evaluated, along with method of evaluation.

D2.10.2 Environmental parameters measured during the test shall be provided on calibration reports for Echelons I and II. Typical ranges are acceptable for Echelon III. These include: laboratory temperature, barometric pressure, and relative humidity.

D2.10.3 Information regarding cleaning methods, where applicable, shall be provided on the calibration reports.

D2.10.4 Calibration reports may include reference to OIML or ASTM classification schemes and tolerances. It is the responsibility of the requestor of the calibration, not the laboratory, to select classifications acceptable for their needs. If conformity is being assessed:

a) items being calibrated shall meet appropriate specifications for evaluation as well as tolerances or state which items are and/or are not evaluated;

b) in instances where magnetism, surface finish, density, or other requirements of the specifications are not evaluated for Echelon I and II, a statement to that effect shall be included on the calibration report.

D2.10.5 The external surface of a mass standard should be free of any sign of abuse or damage. Signs of abuse or misuse include the placement of labels, tags, wires or other material on mass standards. In addition, visible dirt and fingerprints are a sign of misuse for Echelons I and II. It is recommended that the calibration laboratory establish appropriate means for notifying customers regarding any unusual factors, such as signs of abuse regarding the mass standard being tested. Any of these indicators of abuse or damage shall be described in the calibration report.

D2.10.6 Any out-of-tolerance conditions of the mass standards under test identified through the calibration process shall be noted on the calibration report. 


\section{D3 Volume calibrations}

\section{D3.1 General}

The purpose of this section is to provide the specific technical requirements to assess the competence of a calibration laboratory that performs volume calibrations. Volumetric measurements are obtained from mass measurements of known-density materials. Volume calibrations may be determined by either a gravimetric (weighing procedure) or a volume transfer (comparative) procedure. The two types of procedures have different technical requirements, and both are defined here. Note that the type of calibration procedure used affects the achievable uncertainty.

\section{D3.2 Accommodations and environmental conditions}

D3.2.1 Vibration, air currents, rapid temperature fluctuations, and other environmental variations shall be kept to levels such that they do not diminish the validity of the measurement whether by volume transfer methods or the performance of precision balances or scales when gravimetric methods are used.

D3.2.2 Relative humidity shall be monitored more closely when evaporation or condensation may be a concern.

\section{D3.3 Calibration methods and method validation}

D3.3.1 The algorithm chosen for the measurement, the reference standard to be used, and the equipment to be used for a calibration shall be correct for that calibration.

D3.3.2 A documented procedure shall be available in the laboratory.

\section{D3.4 Equipment, standards and reference materials}

\section{D3.4.1 Gravimetric standards and equipment}

D3.4.1.1 Mass standards used as reference standards shall be traceable to the International System of Units through standards maintained by a national metrology institute (such as NIST) and be available at each class and range for which the laboratory is accredited.

D3.4.1.2 When water is used as the medium for gravimetric methods, it shall be deionized or distilled, and its density shall be verified.

D3.4.1.3 For gravimetric procedures the density shall be calculated $/$ measured to $0.000001 \mathrm{~g} / \mathrm{cm}^{3}$.

D3.4.1.4 The quality of water used as a calibration medium shall be of adequate purity (potable) and cleanliness and free from excess air entrapment.

D3.4.1.5 Gravimetric methods shall be performed using weighing equipment with adequate accuracy and precision for the uncertainty of the measurement procedure.

D3.4.1.6 Appropriate control charts or range charts shall be maintained to verify the volume measurement process.

D3.4.1.7 Mass calibration variability shall not be used to estimate variability for gravimetric volume calibrations.

D3.4.1.8 Gravimetric methods require the means to adequately measure barometric air pressure, air temperature, water temperature, and relative humidity of the laboratory environment to perform proper 
buoyancy corrections and calculate or look up accurate water density. Environmental measuring equipment shall be appropriate to support the volume calibration method used.

\section{D3.4.2 Volumetric standards}

D3.4.2.1 Volume standards used as reference standards in the laboratory shall be traceable to the SI through standards maintained by a national metrology institute (such as NIST).

D3.4.2.2 The laboratory shall have appropriate programs and procedures in place for verification and recalibration of its volume standards.

D3.4.2.3 Volumetric methods require accurate temperature measurements. Environmental measuring equipment shall be appropriate to support the volume calibration method used.

D3.4.2.4 Extreme care shall be used to measure water temperatures. The accuracy of water density calculations is severely degraded by inaccurate water temperature measurements and the presence of thermal gradients.

\section{D3.5 Handling of calibration items}

D3.5.1 The volume standard being calibrated shall be free of any sign of abuse or damage, such as dents, chips, improper draining due to lack of cleanliness, and dirty sight gages.

D3.5.2 The laboratory shall have documented procedures to ensure adequate chain-of-custody of calibration items if required by law.

D3.5.3 Procedures shall be documented to ensure adequate tracking glass or metal volumetric standards.

\section{D3.6 Assuring the quality of calibration results}

D3.6.1 Measurement control programs shall be in place and available for review for each measurement type (based upon procedures) and nominal volume range for which calibration data is provided.

D3.6.2 Measurement control techniques shall be implemented, with the resulting data available for review.

D3.6.3 For those situations in which statistical information is not inherent to the process, i.e., simple measurements without built-in redundancy checks, additional measurements shall be made to provide experimental characterization of the measurement that is sufficient for an adequate estimation of the measurement uncertainty.

\section{D3.7 Reporting the results}

D3.7.1 As required by ISO/IEC 17025, calibration reports shall describe the volume standards with sufficient detail to avoid any ambiguity. In addition to those items required by ISO/IEC 17025, calibration reports shall contain the following items:

a) volume;

b) uncertainty;

c) reference temperature; 

d) material of the standard submitted for calibration;
e) thermal coefficient of expansion (assumed, measured, or provided by the manufacturer) used;
f) construction of the item being calibrated;
g) any identifying markings;
h) any tolerances if appropriate (See section regarding conformity statements).

D3.7.2 Environmental parameters measured during the calibration shall be provided on the calibration report as appropriate. These measurements include laboratory air temperature, volume standard temperature, temperature of the medium, barometric pressure, and relative humidity.

D3.7.3 Conformity assessment to a classification scheme is often required for customers using volume standards. If a statement of conformity is being made:

a) the volume standards being calibrated shall meet the appropriate classifications such as NIST, ASTM, API, or OIML;

b) the calibration reports shall clearly identify the classification scheme with revision date to which the conformity assessment was made;

c) conformity statements shall clearly specify to which results they apply and which specifications and tolerances, or parts thereof, are met or not met;

d) out-of-tolerance conditions shall be reported. 


\section{Annex E: Requirements for NVLAP-accredited legal metrology laboratories}

\section{E.1 Scope}

The purpose of this annex is to specify the criteria legal metrology laboratories (also referred to herein as State weights and measures laboratories) shall meet that are in addition to the requirements of ISO/IEC 17025, NIST HB 150, and NIST HB 150-2 and any of its applicable Annexes. These additional requirements apply to legal metrology laboratories that are both NVLAP accredited and NIST Office of Weights and Measures (OWM) recognized.

While NVLAP-accredited laboratories that are not State weights and measures laboratories may choose to follow the requirements in this annex, they will not be assessed to them by NVLAP.

\section{E.2 Training requirements}

Training requirements for State weights and measures laboratories are published in NIST Handbook 143, State Weights and Measures Laboratories Program Handbook, which is available on the NIST OWM website, accessible from www.nist.gov. These requirements are summarized in Table E.1 and shall be met by personnel in State weights and measures laboratories who hold approved signatory status for calibration certificates.

\section{E.3 Regional Measurement Assurance Program (RMAP) Requirements}

The OWM annually holds Regional Metrology Assurance Program (RMAP) training events for coordination of national weights and measures issues, distribution of updated procedures, and ongoing professional development activities. Proficiency testing, detailed in E.4 below, is also included in these RMAP events. Laboratory personnel involved in calibrations covered by their accreditation shall attend the annual OWM Regional Metrology Assurance Program training events as required for ongoing NIST Office of Weights and Measures recognition.

\section{E.4 Proficiency testing (PT) requirements}

PTs are conducted as a part of each RMAP and constitute one of the primary methods used for assessment of competence.

E.4.1 NVLAP-accredited State weights and measures laboratories shall participate in all RMAP PTs for capabilities listed on their NVLAP scope of accreditation and for those capabilities they desire to add to their scope of accreditation.

E.4.2 RMAP proficiency tests are accepted by NVLAP, and State weights and measures laboratories shall include them in the Proficiency Testing Schedule required for submission with each application to NVLAP for accreditation or renewal of accreditation.

E.4.3 Results of RMAP PTs shall be available for review during the NVLAP assessment process.

E.4.4 State weights and measures laboratories having capabilities on their NVLAP scopes of accreditation for which RMAP PT is not available shall ensure that proficiency testing is done by other means. Laboratories may, under the guidance of OWM and following the documented procedures, coordinate "Mini-MAPs" with other laboratories to cover these capabilities. 
Table E.1. NIST Office of Weights and Measures training requirements as published by OWM

\begin{tabular}{|c|c|c|c|}
\hline $\begin{array}{l}\text { Recognition } \\
\text { Level }\end{array}$ & Training Required & For Whom & How Often \\
\hline $\begin{array}{l}\text { All Measurement } \\
\text { Parameters }\end{array}$ & $\begin{array}{l}\text { Regional Measurement Assurance } \\
\text { Program (RMAP)Training }\end{array}$ & $\begin{array}{l}\text { At least one staff } \\
\text { member }\end{array}$ & Annually \\
\hline $\begin{array}{l}\text { Legal Metrology* } \\
\text { Mass, Echelon III } \\
\text { Volume, Echelon } \\
\text { II }\end{array}$ & $\begin{array}{ll}\text { 1. Fundamentals of Metrology (1 } \\
\text { week course) } \\
\text { 2. Introduction and Orientation to } \\
\text { Mass and Volume Procedures* } \\
\text { 3. Fundamentals of Metrology, } \\
\text { Laboratory Auditing Program } \\
\text { (LAP) problems } \\
\text { 4. Successful completion of } \\
\text { proficiency testing }\end{array}$ & $\begin{array}{l}\text { Usually all staff, at } \\
\text { least one staff } \\
\text { member }\end{array}$ & $\begin{array}{l}\text { Once Initially } \\
\text { Refresher } \\
\text { portions } \\
\text { covered during } \\
\text { Regional } \\
\text { Measurement } \\
\text { Assurance } \\
\text { Program } \\
\text { (RMAP) } \\
\text { training }\end{array}$ \\
\hline $\begin{array}{l}\text { Mass Calibration } \\
\text { Echelon III and II }\end{array}$ & $\begin{array}{l}\text { 1. All of the above, plus: } \\
\text { 2. Mass Seminar ( } 2 \text { week course) } \\
\text { 3. Successful completion of } \\
\text { proficiency testing for each area } \\
\text { on the laboratory Scope }\end{array}$ & $\begin{array}{l}\text { Usually all staff, } \\
\text { at least one staff } \\
\text { member }\end{array}$ & $\begin{array}{l}\text { Once Initially } \\
\text { Refresher } \\
\text { recommended } \\
\text { every } 10 \text { years }\end{array}$ \\
\hline $\begin{array}{l}\text { Advanced Mass } \\
\text { Calibration, } \\
\text { Echelon I }\end{array}$ & $\begin{array}{ll}\text { 1. } & \text { All of the above, plus: } \\
\text { 2. Advanced Mass Seminar (1 week } \\
\text { course) } \\
\text { 3. Advanced Laboratory Auditing } \\
\text { Program (LAP) problems } \\
\text { 4. Successful completion of } \\
\text { proficiency testing using } \\
\text { weighing designs } \\
\text { 5. Optional: Advanced Hands-On } \\
\text { Mass Seminar (if available) } \\
\end{array}$ & $\begin{array}{l}\text { At least one staff } \\
\text { member }\end{array}$ & $\begin{array}{l}\text { Once Initially } \\
\text { Refresher } \\
\text { recommended } \\
\text { every } 10 \text { years }\end{array}$ \\
\hline $\begin{array}{l}\text { Volume } \\
\text { Calibration, } \\
\text { Echelon I and II }\end{array}$ & $\begin{array}{ll}\text { 1. } & \text { Legal Metrology Requirements } \\
\text { and Mass Calibration } \\
\text { Requirements noted above } \\
\text { 2. Volume Calibration Course (1 } \\
\text { week) } \\
\text { 3. Successful completion of } \\
\text { proficiency testing for each area } \\
\text { on the laboratory scope using } \\
\text { gravimetric calibrations }\end{array}$ & $\begin{array}{l}\text { Usually all staff, } \\
\text { at least one staff } \\
\text { member }\end{array}$ & $\begin{array}{l}\text { Once Initially } \\
\text { Refresher } \\
\text { recommended } \\
\text { every } 10 \text { years }\end{array}$ \\
\hline $\begin{array}{l}\text { All measurement } \\
\text { parameters in } \\
\text { addition to mass } \\
\text { and volume }\end{array}$ & $\begin{array}{l}\text { 1. Documented evidence of training } \\
\text { 2. Successful completion of } \\
\text { proficiency testing in each area of } \\
\text { the laboratory Scope }\end{array}$ & $\begin{array}{l}\text { At least one, as } \\
\text { needed }\end{array}$ & $\begin{array}{l}\text { At least once; } \\
\text { Refresher as } \\
\text { needed }\end{array}$ \\
\hline
\end{tabular}




\section{E.5 Conformity assessment and calibration intervals}

E.5.1 State weights and measures laboratories commonly have additional regulatory requirements resulting from the adoption into State law or regulation of requirements from documentary standards. When this is the case, State weights and measures laboratories shall meet these additional requirements, when applicable including, but not limited to:

a) assessment of submitted standards for full conformity to specified documentary standards referenced in State law or regulation, except where exemptions to full conformity are noted according to ISO/IEC 17025 or the documentary standards themselves;

b) inclusion on calibration certificates of statements of conformity as assessed in E.5.1a;

c) inclusion on calibration certificates of calibration intervals when such intervals are defined and/or required by State laws or regulations. 